\title{
Association between depression and brain tumor: a systematic review and meta-analysis
}

\author{
Jing Huang ${ }^{1,2}$, Chao Zeng ${ }^{3}$, Juxiong Xiao4, Danwei Zhao5, Hui Tang ${ }^{1,2}$, Haishan \\ $\mathbf{W u}^{1,2}$ and Jindong Chen ${ }^{1,2}$ \\ ${ }^{1}$ Department of Psychiatry, The Second Xiangya Hospital, Central South University, Changsha, Hunan, China \\ ${ }^{2}$ Mental Health Institute of The Second Xiangya Hospital, Central South University, Chinese National Clinical Research \\ Center on Mental Disorders (Xiangya), Chinese National Technology Institute on Mental Disorders, Hunan Key Laboratory \\ of Psychiatry and Mental Health, Changsha, Hunan, China \\ ${ }^{3}$ Department of Thoracic Surgery, Second Xiangya Hospital of Central South University, Changsha, Hunan, China \\ ${ }^{4}$ Department of Urology, Xiangya Hospital, Central South University, Changsha, Hunan, China \\ ${ }^{5}$ Xiangya Medical School, Central South University, Changsha, Hunan, China \\ Correspondence to: Jindong Chen, email: 1048534957@qq.com
}

Keywords: brain tumor, depression, depressive disorder, depressive symptoms, meta-analysis

Received: March 02, $2017 \quad$ Accepted: June 04, $2017 \quad$ Published: August 03, 2017

Copyright: Huang et al. This is an open-access article distributed under the terms of the Creative Commons Attribution License 3.0 (CC BY 3.0), which premits understricted use, distribution, and reproduction in any medium, provided the original author and source are credited.

\section{ABSTRACT}

Background: Patients with brain tumor are in risk of depression or depressive symptoms, but the estimated prevalence varies between studies. The aim of this study is to get a proper summarized estimate of depression prevalence in brain tumor patients.

Methods: Literature search on Pubmed, PsycINFO, and Cochrane library from January 1981 through October 2016. The prevalence of depression or depressive symptoms in brain tumor patients was estimated by screening scales and analyzed using stratified meta-analysis and subgroup analysis. The prevalence of depression level or symptoms during the follow-up periods was detected by secondary analysis.

Results: Among the 37 studies included in this meta-analysis, 25 used a crosssectional design and 12 used longitudinal study. The pooled prevalence was $21.7 \%$ ( $971 / 4518$ individuals, $95 \%$ confidence interval (CI) $18.2 \%-25.2 \%$ ) for overall sample. Lower prevalence was detected in studies with sample size $\geq 100$ than $<100$, lower grade tumor than high grade tumor, studies using clinician-rated depression scales than self-rated or non-depression-specific ones, and in patients from UK, Germany and Italy than USA. After analyzing 6 longitudinal studies, prevalence of depression remained no change in the follow-up periods. No significant differences were observed between study designs and tumor types.

Conclusions: The estimated prevalence of depression or depressive symptoms among brain tumor patients was $\mathbf{2 1 . 7 \%}$, affected by depression assessment type, sample size, tumor grade and country. Diagnosis and treatment of co-morbid depression in brain tumor patients need to be addressed in future studies for better life quality and oncology management. 


\section{INTRODUCTION}

Depression is a severe mental health disorder developed under different circumstances, formally diagnosed by DSM-IV or DSM-V (Diagnostic and Statistical Manual of Mental Disorders $4^{\text {th }}$ edition or $5^{\text {th }}$ edition) $[1,2]$. Depressive symptoms, such as fatigue, loss of interest, decreased energy, feelings of guilt, worthlessness could be main manifestations of depressive disorder or other psychological diseases $[1,2]$. Depression or depressive symptoms among brain tumor patients have been reported by distinct diagnostic clinical interviews with distinct criteria and thresholds [3, 4], which have been linked to the adverse course of the disease, a worsened life quality and even higher rates of mortality [4-8]. However, estimates of the prevalence of depression or depressive symptoms varied greatly, ranging from $2.8 \%$ to $95 \%[9,10]$. Different screening and diagnostic scales were employed to evaluate depression prevalence in brain tumor patients with different age or sex, education level, countries, brain tumor type and grade, thus leading to various findings about the estimated depression prevalence [11-14].

The adverse impacts of depression or depressive symptoms among patients with brain tumor, the various risk factors and the variations between assessment tools, have made it an urgent task to obtain an accurate and reliable depression prevalence in brain tumor patients. The aim of our study is to acquire a proper summary estimate of the depression prevalence and to discuss the reasonable and suitable depression assessment instruments in the clinical setting. Therefore, we conducted a systematic review and meta-analysis from 37 observational studies, to get a summary prevalence of depression among brain tumor patients and help to develop a better identification, prevention and treatment of the depression co-morbidity and original tumor.

\section{RESULTS}

\section{Selection of studies and study characteristics}

The initial search strategy identified 2746 potentially articles: 2615 from PUBMED, 73 from Cochrane library, and 58 from PsycINFO. Figure 1 presented details of the studies included in the meta-analysis. After screening the titles and abstracts according to the selection criteria, we excluded 2622 studies. We also identified additional studies by reference scanning and previous meta-analysis or reviews. Overall, we got a total of 37 eligible studies for further analysis.

\section{Main associations of depression with brain tumor}

These studies provided a total sample of 4518 patients (median sample size $=122$ patients, range $=$ 22-573 patients) including 25 cross-sectional $[4,5,12$,
$14,19,22-24,33-49]$ studies, 12 longitudinal studies $[6,7,13,20,21,50-56]$. No randomized controlled trial was eligible. All 37 studies are prospective research. The average percentage of men in the total sample was $51.3 \%$. 17 studies assessed for depression or depressive symptoms using Hospital Anxiety and Depression Scale (HADS-D) $[4,7,13,14,21,33,35,39-43,45,46,49-51], 6$ used Beck Depression Inventory (BDI) [5, 6, 23, 44, 52, 54, 57], 2 used the Zung Self-Rating Depression Scale (Zung SDS) [51, 58], 2 used Diagnostic and Statistical Manual of Mental Disorders, 4th. Edition (DSM-IV) [12, 47], 10 used other methods $[19,20,22,24,34,36,37,48,53$, 56]. The diagnostic criteria used by the studies were summarized in Table 1. When evaluated by the modified Newcastle-Ottawa scale, out of 5 possible points, 0 studies received 5 points, 6 received 4 points, 18 received 3 points, 9 received 2 points, 4 received 1 point, and 0 received 0 points (detailed criteria were presented in the Supplementary 2).

First, we compared depression prevalence in the overall sample. Random-effects metaanalysis was performed. And the results showed that the pooled prevalence of depression disorder in brain tumor patients was $21.7 \% \quad(971 / 4518$ individuals, $95 \%$ confidence interval (CI) $18.2 \%-25.2 \%$ ) in the overall sample (Figure 2). Significant evidence of between-study heterogeneity was observed in the meta-analysis $\left(\mathrm{I}^{2}=89.3 \%, \mathrm{P}<0.01\right)$. The results of sensitivity analysis were not influenced by an individual study by more than $1 \%$ (Supplementary 3 ).

\section{Subgroup analysis}

We next compared the prevalence of depression or depressive symptoms depending on different demographic groups, depression scales and other characteristics by a series of sub-group analyses (Table 2 and Supplementary 4). No significant differences were observed between studies stratified by cross-sectional vs longitudinal studies (696/3131, $20.7 \%$ [ $95 \%$ CI, $16.2 \%$ to $25.2 \%$ ] vs $275 / 1387$, $24.0 \%$ [ $95 \%$ CI, $18.1 \%$ to $29.8 \%$ ]; test for subgroup differences, $\mathrm{Q}=0.58, \mathrm{P}=0.45$ ), tumor types investigated including glioma only vs multiple tumor types such as glioma, meningioma, pituitary adenoma (340/1908, 19.6\% [95\% CI, $15.6 \%$ to $23.5 \%$ ] vs $(631 / 2610,22.5 \%$ [ $95 \% \mathrm{CI}$, $17.4 \%$ to $27.6 \%$ ]; $\mathrm{Q}=2.89, \mathrm{P}=0.09$ ). Heterogeneity was partly explained by large sample size (sample $\geq 100$ ) vs small sample size (sample <100) $(668 / 3273,19.1 \%[95 \%$ CI, $13.9 \%$ to $24.3 \%$ ] vs $303 / 1245,23.8 \%$ [ $95 \%$ CI, $19.2 \%$ to $28.4 \%]$ ); $\mathrm{Q}=9.18, \mathrm{P}<0.01$ ), countries patients recruited (studies in the United States vs UK vs Germany vs Italy vs elsewhere $(420 / 1899,24.3 \%$ [ $95 \% \mathrm{CI}, 16.9 \%$ to $31.7 \%$ ] vs $119 / 831,14.8 \%$ [ $95 \%$ CI, $10.1 \%$ to $19.6 \%$ ] vs $132 / 510$, $16.6 \%$ [ $95 \%$ CI, $4.2 \%$ to $29.1 \%$ ] vs $68 / 344,21.7 \%$ [ $95 \%$ CI, $10.9 \%$ to $32.4 \%$ ] vs $232 / 934,27.7 \%$ [ $95 \%$ CI, $20.4 \%$ to $35.1 \%$ ]; $\mathrm{Q}=33.01, \mathrm{P} \leq 0.01)$ ). Significant prevalence 
difference between high grade glioma (WHO I and II) vs low grade glioma (WHO III and IV) was also detected (48/418, $19.5 \%$ [95\% CI, $13.9 \%$ to $25.1 \%$ ] vs $180 / 1133$, $15.4 \%$ [95\% CI, $6.4 \%$ to $24.4 \%$ ]; $\mathrm{Q}=16.57, \mathrm{P}<0.01$ ) (Supplementary 5).

When we stratified studies by depression scales, high heterogeneity was detected $(\mathrm{Q}=273.83, \mathrm{P} \leq 0.01)$. Then we divided all the depression scales used by these studies into clinician-rated scales, self-rated scales and non-depression-specific scales, based on the type of depression assessment. Clinician-rated scales included DSM-IV, Hamilton Rating Scale for Depression (HDS) $\geq 17$ [59], General Practitioner (GP) records [56], Inpatient notes [24] and Physical reports [36]. And self-rated scales included HADS-D with a cut-off $\geq 11$ [60], and Patient Health Questionnaire-9 (PHQ-9) $\geq 10$ $[61,62]$, BDI $\geq 10$ [63], Beck depression inventory-II (BDI-II) $\geq 14$ [64], Center for Epidemiologic StudiesDepression Scale (CES-D) $\geq 16$ [65], HADS-D $\geq 8$ [60], Zung SDS $\geq 41$ [66]. Other studies which use nondepression-specific diagnostic methods were grouped as non-depression-specific scales, consist of Profiles of Mood States Short Form (POMS-SF) $\leq 50$ [67], 36-Item Short Form Health Survey (SF-36) $\leq 60$ [68], open ended interviews, as well as Brief Cope Scale (BCS). DSM$\mathrm{IV}$, as a clinician-rated scales, has obtained a status as the international standard for Major Depressive Disorder [2]. And HDS, GP records, inpatient notes and physical reports are physician-based depression symptoms rating in clinical practice. Self-rated depression scales, which are also widely applied in clinical setting, are considered as good screening tools for depressive disorder or symptoms. Non-depression-specific scales often recognize distressing emotional symptoms not restricted to depressive symptoms [69].

The high heterogeneity between studies could partly be explained by type of depression assessment (clinicianrated scales vs self-rated scales vs non-depressionspecific scales (172/916, 19.1\% [95\% CI, 14.9\% to $23.2 \%$ ] vs $(666 / 2711,20.6 \%$ [ $95 \% \mathrm{CI}, 17.2 \%$ to $23.1 \%$ ] vs $(133 / 891,14.8 \%$ [95\% CI, $8.5 \%$ to $21.0 \%$ ]; $\mathrm{Q}=14.96$, $\mathrm{P}<0.01)$ ) (Supplementary 3E). There were no significant differences between studies in which estimates was made by clinician-rated scales $(\mathrm{Q}=2.57, \mathrm{P}=0.63)$, suggesting that variation between clinical rated tools did not explain the heterogeneity in the symptom prevalence estimates. Conversely, there were significant differences between estimates using self-rated scales $(\mathrm{Q}=16.35, \mathrm{P}<0.01)$ and non-depression scales $(\mathrm{Q}=202.44, \mathrm{P}<0.01)$. These results indicated that in the clinical setting, physician based assessing tools are more stable and consistent for depression diagnosis.

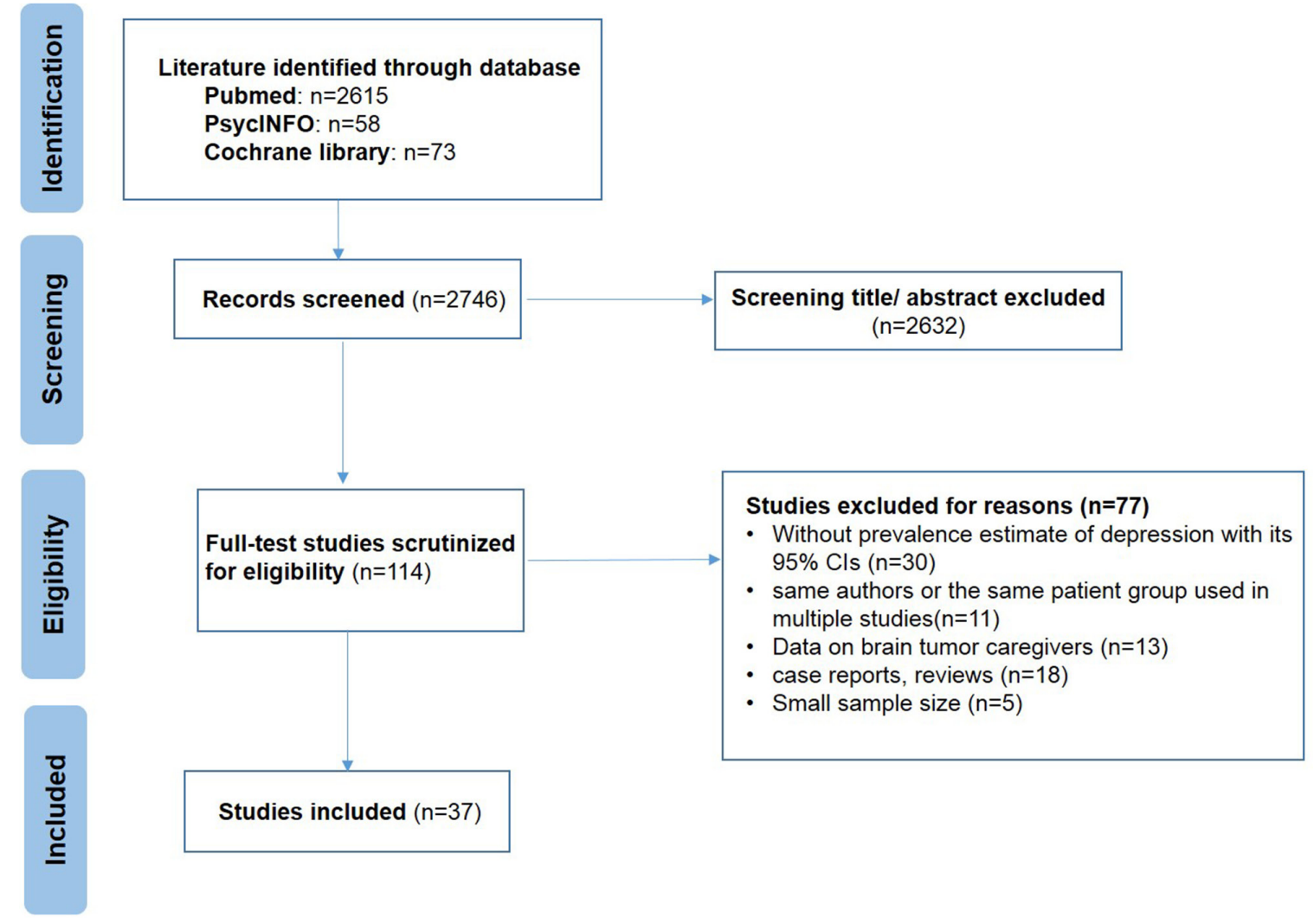

Figure 1: Meta-analysis flowchart for identifying studies on the prevalence of depression among brain tumor patients. 
Table 1: Characteristics of studies included in this systematic review and meta-analysis

\begin{tabular}{|c|c|c|c|c|c|c|c|c|c|c|c|c|c|c|c|c|}
\hline First author & Year & Country & Study design & Recuitment & Patients, $\mathbf{n}$ & $\begin{array}{c}\text { Male } \\
\text { patients, } \\
\text { n (\%) }\end{array}$ & $\begin{array}{c}\text { Age, } y, \\
\text { mean }\end{array}$ & $\begin{array}{c}\text { Brain tumor } \\
\text { type }\end{array}$ & $\begin{array}{l}\text { WHO low- } \\
\text { grade, } n\end{array}$ & $\begin{array}{c}\text { WHO } \\
\text { high- } \\
\text { grade, } n\end{array}$ & Surgery,\% & $\begin{array}{l}\text { Education }>\text { high } \\
\text { school, } \%\end{array}$ & Married, \% & $\begin{array}{c}\text { Previous } \\
\text { psychiatric } \\
\text { illness, \% }\end{array}$ & White,\% & Depression scale \\
\hline Hickmann & 2016 & Switzerland & Longitudinal & Prospective & 83 & 43.4 & 51.9 & multiple & 51 & 31 & 98.8 & 30 & NR & NR & NR & BDI \\
\hline Jenkins & 2015 & Australia & cross-sectional & Prospective & 33 & NR & 45.75 & multiple & 0 & 30 & NR & NR & NR & NR & NR & HADS-D \\
\hline WELLISCH & 2002 & USA & cross-sectional & Prospective & 89 & 55 & 43.2 & multiple & NR & 39 & 73 & 67.1 & 61.8 & 15.8 & NR & DSM-IV \\
\hline Arnold & 2008 & USA & cross-sectional & Prospective & 363 & 58 & 43.7 & multiple & 219 & 144 & NR & 83 & 76 & 5 & 95 & PHQ-9 \\
\hline Anderson & 1999 & UK & cross-sectional & Prospective & 40 & 60 & 44 & glioma & 24 & 16 & 83 & NR & 70 & NR & NR & HDS \\
\hline Davies & 1996 & UK & Longitudinal & Prospective & 75 & 69 & NR & multiple & 0 & 75 & NR & NR & 78 & NR & 93 & $\begin{array}{l}\text { open ended } \\
\text { interviews }\end{array}$ \\
\hline Pringle & 1999 & UK & cross-sectional & Prospective & 109 & 56.88 & NR & multiple & 53 & 32 & 93 & NR & NR & NR & NR & HADS-D \\
\hline Litofsky & 2004 & USA & Longitudinal & Prospective & 573 & 58 & 55 & glioma & 0 & 598 & 81.4 & NR & 80 & NR & 92.5 & SF-36 \\
\hline Pelletier & 2002 & Canada & cross-sectional & Prospective & 58 & 51.67 & 41.1 & multiple & 18 & 34 & 90 & 95 & 66.6 & NR & NR & BDI-II \\
\hline Edelstein & 2015 & USA & cross-sectional & Prospective & 73 & 60.3 & NR & glioma & 0 & 73 & NR & NR & 83.6 & NR & NR & CES-D \\
\hline Wenz & 2015 & Germany & cross-sectional & Prospective & 58 & 72.2 & 62.6 & meningioma & 58 & 0 & 77.9 & NR & NR & 20.83 & NR & BCS \\
\hline Piil & 2015 & Denmark & Longitudinal & Prospective & 28 & 63.3 & 60 & glioma & 0 & 30 & 76.67 & NR & 80 & NR & NR & HADS-D \\
\hline Rahman & 2015 & Australia & cross-sectional & Prospective & 81 & 58 & NR & multiple & 30 & 51 & 100 & 58 & NR & NR & NR & HADS-D \\
\hline Leistner & 2015 & Germany & cross-sectional & Prospective & 247 & 37 & 53.25 & $\begin{array}{l}\text { pituitary } \\
\text { adenoma }\end{array}$ & 0 & 0 & 66.7 & NR & NR & NR & NR & BDI \\
\hline Lucchiari & 2014 & Italy & cross-sectional & Prospective & 73 & 66 & 48.9 & glioma & 0 & 73 & NR & 17.8 & NR & NR & NR & HADS-D \\
\hline Janda & 2007 & Australia & cross-sectional & Prospective & 75 & 45.9 & 74.6 & multiple & 31 & 44 & NR & 70.2 & 62.2 & NR & NR & HADS-D \\
\hline Vossen & 2014 & Netherlands & cross-sectional & Prospective & 136 & 22 & 59.1 & meningioma & 134 & 2 & 71 & 40 & NR & NR & NR & HADS-D \\
\hline ANGELO & 2008 & Italy & Longitudinal & Prospective & 72 & 43.1 & NR & multiple & 22 & 10 & NR & 13.9 & 79.17 & NR & NR & Zung SDS \\
\hline Bunevicius & 2012 & Lithuania & Longitudinal & Prospective & 226 & 31 & 55.6 & multiple & 3 & 65 & $\mathrm{NR}$ & NR & NR & 7.1 & NR & HADS-D \\
\hline Andrewes & 2013 & Australia & cross-sectional & Prospective & 32 & 43.8 & 52 & multiple & 0 & 29 & NR & 43.8 & NR & NR & NR & HADS-D \\
\hline Goebel & 2012 & Germany & Longitudinal & Prospective & 76 & 33 & 54.42 & meningioma & 52 & 24 & 100 & NR & 84 & 11.8 & NR & HADS-D \\
\hline Keeling & 2012 & UK & cross-sectional & Prospective & 74 & 46 & 38.3 & multiple & 64 & 0 & 68.66 & NR & NR & NR & $\mathrm{NR}$ & HADS-D \\
\hline Goebel & 2012 & Germany & cross-sectional & Prospective & 172 & 48.8 & 52.4 & multiple & 93 & 78 & NR & NR & NR & NR & NR & HADS-D \\
\hline Santini & 2012 & Italy & Longitudinal & Prospective & 22 & 45 & NR & multiple & 14 & 8 & 100 & NR & NR & NR & NR & BDI \\
\hline Mainio & 2006 & Finland & Longitudinal & Prospective & 77 & 38.6 & $\mathrm{NR}$ & glioma & 16 & 15 & NR & NR & NR & NR & NR & BDI \\
\hline Kilbride & 2007 & UK & Longitudinal & Prospective & 51 & 54.9 & 55 & multiple & 3 & 42 & 100 & NR & NR & NR & NR & HADS-D \\
\hline Rooney & 2011 & UK & Longitudinal & Prospective & 155 & 57.4 & NR & glioma & 22 & 133 & 74.8 & NR & 80 & 18.06 & NR & DSM-IV \\
\hline Goebel & 2011 & Germany & cross-sectional & Prospective & 180 & 48.3 & 52.7 & multiple & NR & 78 & NR & NR & 75.6 & NR & NR & HADS-D \\
\hline Armstrong & 2002 & USA & Longitudinal & Prospective & 57 & NR & 40.77 & glioma & 57 & 0 & 67 & NR & NR & NR & NR & BDI \\
\hline Brown & 2006 & USA & cross-sectional & Prospective & 185 & 65.5 & NR & glioma & 0 & 185 & 83.5 & NR & NR & NR & NR & POMS-SF \\
\hline CHANG & 2003 & USA & cross-sectional & Prospective & 499 & 55.7 & $\mathrm{NR}$ & glioma & 0 & 499 & 91.8 & NR & NR & NR & NR & Physician report \\
\hline Giovagnoli & 1996 & Italy & cross-sectional & Prospective & 125 & 101 & 60 & multiple & NR & 11 & 90 & NR & NR & 70 & NR & NR \\
\hline Grant & 1994 & UK & cross-sectional & Prospective & 48 & NR & NR & glioma & NR & NR & NR & NR & NR & NR & NR & HADS-D \\
\hline Kaplan & 2000 & USA & cross-sectional & Prospective & 33 & NR & 33 & multiple & 0 & 33 & NR & NR & 75.8 & NR & $\mathrm{NR}$ & BDI \\
\hline McGovern & 2003 & USA & cross-sectional & Prospective & 33 & NR & $\mathrm{NR}$ & multiple & 0 & 33 & NR & NR & NR & NR & NR & Inpatient notes \\
\hline Rooney & 2009 & UK & cross-sectional & Prospective & 100 & 55 & NR & glioma & NR & NR & NR & NR & NR & NR & NR & GP records \\
\hline Goebel & 2010 & Germany & cross-sectional & Prospective & 150 & 43.3 & 53.15 & multiple & 73 & 77 & NR & NR & 64.3 & NR & NR & HADS-D \\
\hline
\end{tabular}

BDI, Beck Depression Inventory; HADS-D, Depression Subscale of Hospital Anxiety and Depression Scale; DSM-IV, Diagnostic and Statistical Manual of Mental Disorders, 4th. Edition; PHQ-9; Patient Health Questionnaire-9; HDS, Hamilton Rating Scale for Depression; SF-36, 36-Item Short Form Health Survey; BDI-II, Beck Depression Inventory-II; CES-D, Center for Epidemiologic Studies-Depression Scale; BCS, Brief Cope Scale; Zung SDS, Zung Self-rating Depression Scale,

\section{Secondary analysis}

Of the 12 longitudinal studies, we detected prevalence of depression or depressive symptoms at different time points to figure out whether there was an increased prevalence with increasing calendar year or in further analysis. Patients after diagnosis at baseline were involved in follow-up studies. Follow-up time points varied across studies, from 3 months to 12 months. 6 studies were excluded because they are in lack of available raw data on prevalence of depression or their main focus is not on the outcome and effect of depression or depressive symptoms $[39,50,52,53,55,70]$. After analyzing the 
remaining 6 longitudinal studies [6, 7, 20, 40, 51, 54], brain tumor patients presented with a slightly higher prevalence of depression in the follow-up period (Relative Increase Ratio:1.35, 95\% CI $(1.04,1.76))(\mathrm{P}=0.025)$ (Table 3). Sensitivity analysis for the secondary analysis revealed that Angelo's study has substantial influence on the final result [51]. After moving out this study, the result showed that prevalence of depression remained no change in further analysis. (Relative Increase Ratio: 1.20, 95\% $\mathrm{CI}(0.91,1.59))(\mathrm{P}=0.204)$.

\section{Publication bias}

Publication bias was investigated by funnel plot (Figure 3) and Egger test. Significant publication bias among studies was detected by visual inspection of funnel plot, and there was asymmetrical distribution of the studies indicating publication bias (Egger test $\mathrm{P}=0.012$ ).

\section{DISCUSSION}

This systematic review and meta-analysis involved 4518 patients with intracranial tumor from 37 observational studies and demonstrated a high prevalence of depression or depressive symptoms (overall prevalence $21.7 \%$; $95 \%$ CI $18.2 \%-25.2 \%$ ). The prevalence is higher than that in normal population, which is up to 4 $\%$ of men and $8 \%$ of women [71]. The reason is possibly awareness of disease state and the effect of treatment. But the prevalence is comparably lower than that in patients with diabetes and breast cancer, partly due to its rapid disease progression [72-76]. Brain tumor patients with depression or depressive symptoms are reported to have worse health related quality of life (HRQoL), elevated risk of suicide, more medical complications and worse survival $[5,20,44,54,57]$. Unfortunately, only part of patients with depression are properly treated [20]. Thus assessment

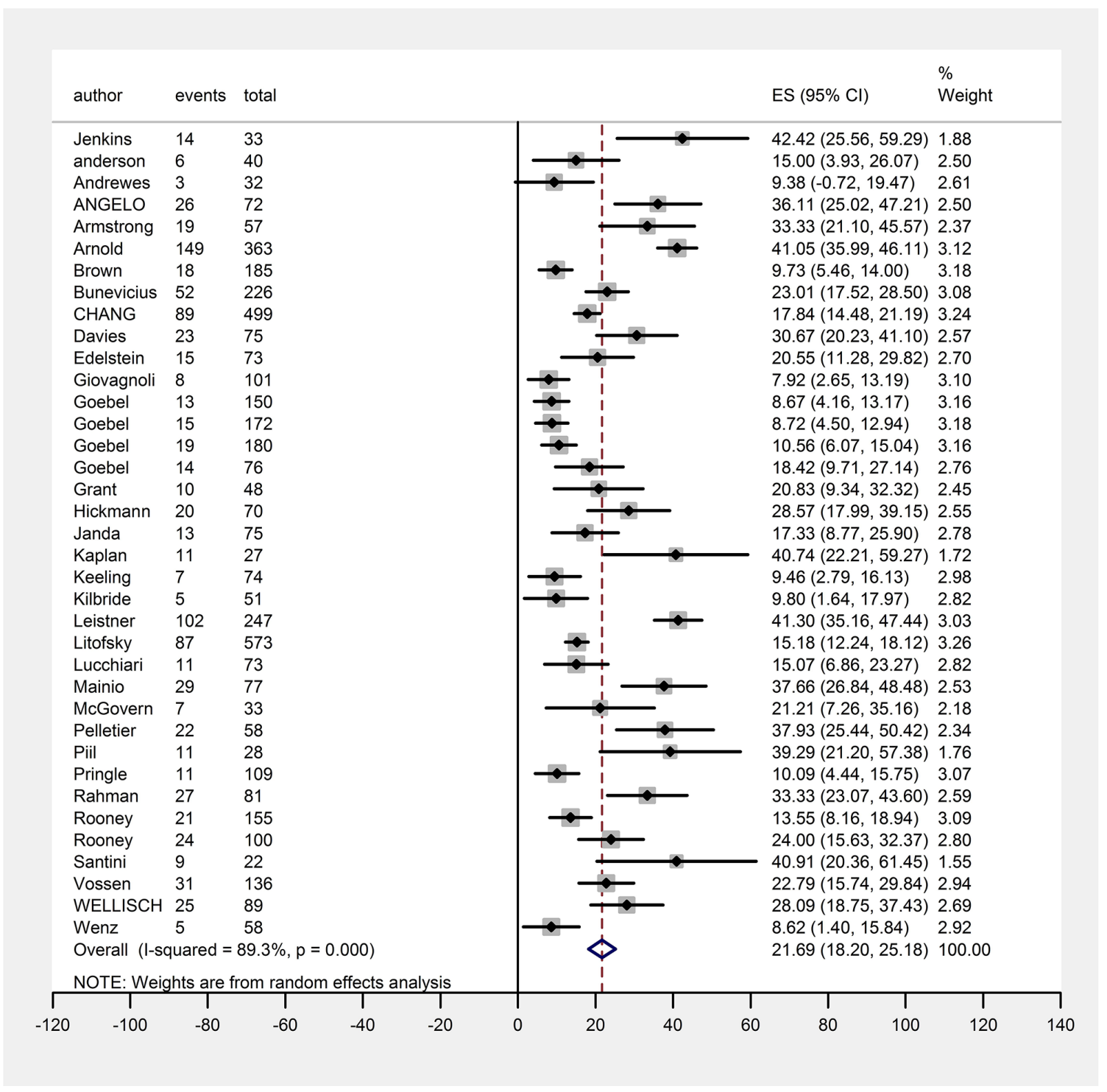

Figure 2: Forest plot for random-effects meta-analysis showing pooled prevalence of depression in overall sample. 
Table 2: Meta-analyses of the prevalence of depression or depressive symptoms among brain tumor patients stratified by study-level characteristics

\begin{tabular}{|ccccc} 
No. of studies & $\begin{array}{c}\text { No of patients } \\
\text { with depression }\end{array}$ & $\begin{array}{c}\text { Total number } \\
\text { of patients }\end{array}$ & $\begin{array}{c}\text { Prevalence of } \\
\text { depression, } \\
\%(95 \% \mathrm{Cl})\end{array}$ & $\begin{array}{c}\text { P for subgroup } \\
\text { differences }\end{array}$ \\
\hline
\end{tabular}

Study Design

Longitudinal

cross-sectional

12

275

696

1387

3131

$24.0(18.1-29.8)$

0.45

Country

USA

UK

Germany

Italy

Others

Sample size

$\geq 100$

15

22

420

1899

119

132

232

668

3273

1245

$<100$

Tumor type

glioma

12

25

340

2610

631

172

639

2711

133
831

510

344

934

$19.1(13.9-24.3)$

$<0.01$

1908

916

$20.7(16.2-25.2)$

24.3 (16.9-31.7)

$<0.01$

14.8 (10.1-19.6)

16.6 (4.2-29.1)

21.7 (10.9-32.4)

27.7 (20.4-35.1)

$23.8(19.2-28.4)$

$19.6(15.6-23.5)$

0.09

22.5 (17.4-276)

$19.1(14.9-23.2)$

0.018

$20.6(17.2-23.1)$

891

$14.8(8.5-21.00)$

Table 3: Secondary analysis of 6 longitudinal studies reporting prevalence estimates with increasing calendar year in further analysis

\begin{tabular}{|c|c|c|c|c|c|c|c|c|c|c|}
\hline & & & & Baseline & & & Follow-up & & & Comparison \\
\hline First author & Year & $\begin{array}{l}\text { Depression } \\
\text { scale }\end{array}$ & Follow-up & $\begin{array}{c}\text { No of patients } \\
\text { with depression }\end{array}$ & $\begin{array}{l}\text { Total number } \\
\text { of patients }\end{array}$ & $\begin{array}{c}\text { Prevalence of } \\
\text { depression, } \%(95 \% \mathrm{Cl})\end{array}$ & $\begin{array}{l}\text { No of patients } \\
\text { with depression }\end{array}$ & $\begin{array}{c}\text { Total number } \\
\text { of patients }\end{array}$ & $\begin{array}{c}\text { Prevalence of } \\
\text { depression, } \%(95 \% \mathrm{Cl})\end{array}$ & $\begin{array}{c}\text { Relative } \\
\text { increase } \\
\text { ratio, } \%(95 \% \mathrm{Cl})\end{array}$ \\
\hline Hickmann & 2016 & $\mathrm{BDI} \geq 10$ & $3 \mathrm{mo}$ & 19 & 70 & $27.1(16.7,37.6)$ & 20 & 70 & $28.6(18.0,39.2)$ & $1.05(0.52,2.14)$ \\
\hline Litofsky & 2004 & SF $-36 \leq 60$ & $6 \mathrm{mo}$ & 87 & 573 & $15.2(12.2,18.1)$ & 42 & 193 & $21.8(15.9,27.6)$ & $1.43(0.96,2.14)$ \\
\hline Piil & 2015 & HADS-D $\geq 11$ & $6 \mathrm{mo}$ & 11 & 28 & $39.3(21.2,57.4)$ & 5 & 26 & $19.2(4.0,34.4)$ & $0.49(0.15,1.60)$ \\
\hline ANGELO & 2008 & Zung SDS $\geq 41$ & $6 \mathrm{mo}$ & 7 & 72 & $9.7(2.9,16.6)$ & 26 & 72 & $36.1(25.0,47.2)$ & $3.71(1.52,9.10)$ \\
\hline Goebel & 2012 & HADS-D $\geq 11$ & $6 \mathrm{mo}$ & 9 & 76 & $11.8(4.6,19.1)$ & 14 & 76 & $18.4(9.7,27.1)$ & $1.56(0.64,3.81)$ \\
\hline Mainio & 2006 & $\mathrm{BDI} \geq 10$ & $3 \mathrm{mo}$ & 27 & 77 & $35.1(24.4,45.7)$ & 29 & 81 & $35.8(25.4,46.2)$ & $1.02(0.55,1.88)$ \\
\hline
\end{tabular}

of depression or depressive symptoms in patients with brain tumor is essential for clinical practitioners to improve prognosis and HRQoL. The role of depression in intracranial tumor patients should be well understood and studied to develop proper management as well.

In explaining the heterogeneity of this meta-analysis, we stratified the groups according to types of depression assessment and found no significant variation in prevalence estimate with clinician-rated depression scales. There were no significant differences between studies in which estimates was made by clinician-rated scales, suggesting that variation between clinical rated tools did not explain the heterogeneity in the symptom prevalence estimates. These results indicated that in the clinical setting, physician based assessing tools are reliable and consistent for depression diagnosis. However, self-rated scales and non-depression-specific scales varied 
largely in evaluating the estimate prevalence, especially selfrated scales that yielded significantly higher estimates, which could partly explain the heterogeneity [77].

There seems no consensus to define the best standardized scale for assessing the depression or depressive symptoms in brain tumor patients [77]. Therefore, how to accurately assess the prevalence of depression or depressive symptoms and distinguish it from natural reaction is very important [69]. In the study of the association between depression and insulin resistance, Kan et al. divided assessing tools into clinician diagnostic interviews and self-report measures, and observed higher prevalence in the latter group [78]. DSV-IV, HDS and other clinician diagnostic interviews, are validated and consistent in the identification of depression or depressive symptoms. And the patient-reported depression is usually discordant with clinician diagnostic scales [20]. The classification strategy, indeterminate cut-off point and analyzed results indicated the less accuracy and consistence of self-report measures in the diagnosis of depression. However, some self-report measures such as BDI/II, Zung SDS and HADS-D with reasonable cut-off and specific questionnaire could help to screen and assess depression prevalence among brain tumor patients, because they may save time, identify comorbid conditions even with inadequate provider knowledge of the diagnostic criteria, avoid the absence of anonymity and monitor the severity easily [69]. Moreover, nondepression-specific screening methods such as POMSSF and SF-36 would be better limited into primary epidemiologic screening rather than definite diagnosis, for they recognize distressing emotional symptoms not restricted to depressive symptoms and are associated with low specificity and accuracy [77]. Besides, different depression scales using categorical (yes/no decisions) or dimensional assessment (determined by score or cut-off point) have different estimates of depression, contributing to the heterogeneity [79].

On the other hand, we also investigated correlations between depression prevalence and study characteristics depending on study design, tumor type, sample size, tumor grade, and Newcastle-Ottawa scores. No significant correlation with depression prevalence was found in study design, tumor type and Newcastle-Ottawa scores. Patients with high grade glioma show higher depression prevalence than those with low grade brain tumor. Studies of smaller sample size got an increased depression estimate, suggesting the presence of publication bias. Of the countries patients were recruited, patients from USA had a higher depression prevalence estimate than other countries. This could partly explained by the common use of self-rated assessment tools such as $\mathrm{PHQ} \geq 10$, BDI $\geq 10$

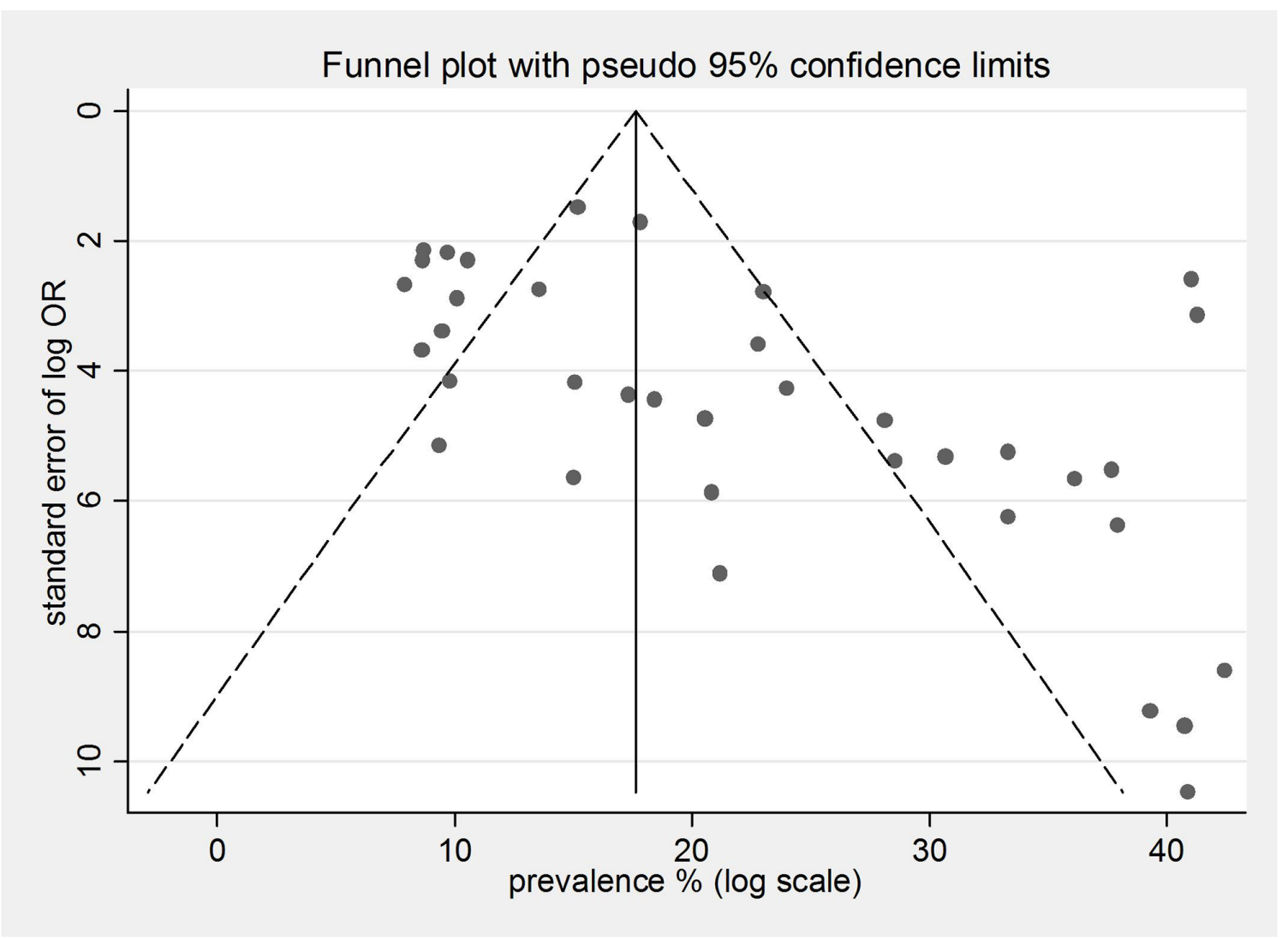

Figure 3: Funnel plot for the included studies that examined small study effects. The dashed line represents $95 \%$ confidence intervals. Circles represent individual studies. 
and CES-D $\geq 16[20,23,37]$ and non-depression-specific scales such as POMS-SF [22] and SF-36 [20] in USA.

A secondary analysis during follow-up periods didn't show an increased prevalence of depression among brain tumor patients after the primary diagnosis. The Relative Increase Ratio in depressive symptoms $1.20,95 \%$ CI $(0.91,1.59)$, which indicated no remission of depressive symptoms over time. Limited raw data for secondary analysis also indicated the lack of proper monitoring and management of co-morbid depressive symptoms for patients with brain tumor [51].

The study also has some limitations. Firstly, a high heterogeneity in different studies has emerged, although it could be partly explained by different tumor grade, countries and screening methods. Unexamined factors, such as the institutional culture may also play an important role in it [80]. Secondly, the studies included in this meta-analysis didn't allow understanding the prevalence of depression in brain tumor patients compared with depression prevalence in extracranial tumor patients. It will be better if more stratified cohort studies are conducted to compare different types of brain tumor with health control. More longitudinal studies with constant assessment and management during follow-up periods are necessary to generate more accurate analysis of depression prevalence and prognosis in further studies. Although with few evidence, it remained to be settled down that whether depression symptoms have significant impact on tumor progression and patients' survival. Diagnosis and treatment of co-morbid depression in brain tumor patients need to be addressed by more studies, and antidepressant therapy or psychotherapeutic intervention for those with co-morbid depression would lead to better life quality and oncology management $[19,20]$.

\section{MATERIALS AND METHODS}

\section{Search strategy and inclusion criteria}

We searched on PUBMED, PsycINFO and Cochrane library for all peer-reviewed English-language literature from January 1981 through October 2016. The key words used for the database search were: "brain tumor," OR "intracranial tumors" OR "carcinoma, intracranial," AND "depression," OR “depressive symptoms," OR “depressive disorders," and the individual corresponding free terms to find more relevant studies (full details of the search strategy are provided in the Supplementary 1). We also searched reviews and meta-analyses to identify studies that may be missed in the former literature searches. Furthermore, all citations in the retrieved articles were obtained and reviewed in full text to search for additional eligible studies [15].

The strategies we used for quality assessment and design protocol is Preferred Reporting Items for Systematic Reviews and Meta-Analyses (PRISMA-P)
2015 guideline [16] (Supplementary 6), which consists of a detailed, well-described checklist for administrative information, introduction, and methods to promote accountability, research integrity, and transparency of the meta-analysis. In addition, we used a modified version of the Newcastle-Ottawa Scale to assess the quality of studies included in systematic reviews and meta-analysis [17]. This scale assessed the quality of studies in the following parts: sample representativeness, sample size, comparability between respondents and non-respondents, outcome of depression diagnosis, and statistical quality (full details in the Supplementary 2). Studies with scores $\geq 3$ points were assessed as low risk of bias, and with scores $<3$ were in high risk of bias.

All studies published were included if 1) they could be defined as an observational study or a randomized controlled trial which involved patients with brain tumor; 2) All depression screening scales were accepted in the analysis; 3) The diagnosis of brain tumor was according to the guideline of the 2016 World Health Organization (WHO) Classification of Tumors of the Central Nervous System (CNS) in the analysis [18]. We excluded studies without full reports; studies included $<20$ patients; nonEnglish-language studies; case reports. Only the most informative and/or the recent one will be included if they came from the same authors or the same patient group used in multiple reports.

Two investigators ( $\mathrm{J}$. Huang and Chao Zeng) independently performed a systematic review of all identified citations. Papers focusing on selected patients but potentially reporting data about depression were selected for full-text review and checked for eligibility.

\section{Data extraction and quality assessment of included studies}

A standardized data extraction was used by two investigators (J. Huang and Chao Zeng) and checked by the other authors. Any discrepancies were settled by consensus. The following data was abstracted from all included studies: study design, year, country, patients involved, tumor grade, education levels, diagnostic or screening method and prevalence. The demographic and clinical characteristics of the publications included were summarized in Table. When more than one point prevalence estimate of depression would have been recorded in longitudinal studies within the year, the overall period prevalence for the time period was used. It should be also noted that in 10 studies, data were recorded separately for high-grade glioma and low-grade glioma clearly on depression prevalence [4, 6, 7, 14, 19-24].

\section{Statistical analysis}

The prevalence estimates of depression comorbidity was calculated by random-effects meta- 
analysis that accounted for between- study heterogeneity $[15,25,26]$. Statistical heterogeneity among studies was assessed using the $\chi 2$ test on Cochran's Q statistic and by calculating $\mathrm{I}^{2}$ [27]. $\mathrm{I}^{2}$ values of $25 \%, 50 \%$, and $75 \%$ were defined as low, moderate, and high heterogeneity separately [28]. An $\mathrm{I}^{2}$ value greater or equal than $50 \%$ indicated considerable levels of heterogeneity [27, 28]. We also conducted a sensitivity analysis by serially excluding each study and repeating the meta-analysis to evaluate whether the results were affected statistically significantly by individual studies. Publication bias was evaluated by using funnel plots and the Egger test [29, 30]. Summary estimates of depression for patients with brain tumor were analyzed using Strata software (version 12.1; Stata Corp, College Station, TX). Forest plots were constructed as well. In all analyses, p value $<0.05$ was considered statistically significant. Where appropriate, if information was available, we compared results from different studies separately based on their characteristics (study design, country, tumor type, sample size, tumor type, tumor grade and diagnostic accuracy) using stratified meta-analysis and subgroup analysis $[31,32]$.

\section{Abbreviations}

BDI: Beck Depression Inventory; HADS-D: Depression Subscale of Hospital Anxiety and Depression Scale; DSM-IV: Diagnostic and Statistical Manual of Mental Disorders, 4th. Edition; PHQ-9: Patient Health Questionnaire-9; HDS, Hamilton Rating Scale for Depression; SF-36: 36-Item Short Form Health Survey; BDI-II, Beck Depression Inventory-II; CES-D: Center for Epidemiologic Studies-Depression Scale; BCS, Brief Cope Scale; Zung SDS: Zung Self-rating Depression Scale; POMS-SF: Profiles of Mood States Short Form; GP: General Practitioner (family physician); SF-36: 36Item Short Form Health Survey; NR: not applicable.

\section{Author contributions}

Jing Huang and Chao Zeng reviewed literature and prepared the manuscript. Juxiong Xiao, Danwei Zhao, Hui Tang and Haishan Wu did data extraction and quality assessment. Jindong Chen supervised all the work.

\section{CONFLICTS OF INTEREST}

None declared.

\section{FUNDING}

This work was supported by Hunan Provincial Science and Technology Department, P. R. China (2012FJ6086) and National Natural Science Foundation of China (81501163).

\section{REFERENCES}

1. Zabel D. Diagnostic and statistical manual of mental disorders. RQ. 1995; 34:531-533.

2. American Psychiatric Association. (2013). Diagnostic and statistical manual of mental disorders (DSM-5®). American Psychiatric Association.

3. Pranckeviciene A, Bunevicius A. Depression screening in patients with brain tumors: a review. CNS Oncol. 2015; 4:71-78.

4. Lucchiari C, Botturi A, Silvani A, Lamperti E, Gaviani P, Innocenti A, Finocchiaro CY, Masiero M, Pravettoni G. Cognitive strategies and quality of life of patients with highgrade glioma. Support Care Cancer. 2015; 23:3427-3435.

5. Pelletier G, Verhoef MJ, Khatri N, Hagen N. Quality of life in brain tumor patients: the relative contributions of depression, fatigue, emotional distress, and existential issues. J Neurooncol. 2002; 57:41-49.

6. Mainio A, Tuunanen S, Hakko H, Niemela A, Koivukangas J, Rasanen P. Decreased quality of life and depression as predictors for shorter survival among patients with lowgrade gliomas: a follow-up from 1990 to 2003. Eur Arch Psychiatry Clin Neurosci. 2006; 256:516-521.

7. Piil K, Jakobsen J, Christensen KB, Juhler M, Jarden M. Health-related quality of life in patients with high-grade gliomas: a quantitative longitudinal study. J Neurooncol. 2015; 124:185-195.

8. McCarty S, Eickmeyer SM, Kocherginsky M, Keeshin S, Shahpar S, Semik P, Wong AW. Health-related quality of life and cancer-related symptoms during interdisciplinary outpatient rehabilitation for malignant brain tumor. Am J Phys Med. 2017.

9. Fox SW, Lyon D, Farace E. Symptom clusters in patients with high-grade glioma. J Nurs Scholarsh. 2007; 39:61-67.

10. Palese A, Cecconi M, Moreale R, Skrap M. Pre-operative stress, anxiety, depression and coping strategies adopted by patients experiencing their first or recurrent brain neoplasm: an explorative study. Stress Health. 2012; 28:416-425.

11. Rooney AG, Carson A, Grant R. Depression in cerebral glioma patients: a systematic review of observational studies. J Natl Cancer Inst. 2011; 103:61-76.

12. Rooney AG, McNamara S, Mackinnon M, Fraser M, Rampling R, Carson A, Grant R. Frequency, clinical associations, and longitudinal course of major depressive disorder in adults with cerebral glioma. J Clin Oncol. 2011; 29:4307-4312.

13. Goebel S, Kaup L, Wiesner CD, Mehdorn HM. Affective state and cognitive functioning in patients with intracranial tumors: validity of the neuropsychological baseline assessment. Psychooncology. 2013; 22:1319-1327.

14. Keeling M, Bambrough J, Simpson J. Depression, anxiety and positive affect in people diagnosed with low-grade tumours: the role of illness perceptions. Psychooncology. $2013 ; 22: 1421-1427$. 
15. Borenstein M, Hedges LV, Higgins JP, Rothstein HR. A basic introduction to fixed-effect and random-effects models for meta-analysis. Res Synth Methods. 2010; 1:97-111.

16. Howard BM, Gursel DB, Bleau AM, Beyene RT, Holland EC, Boockvar JA. EGFR signaling is differentially activated in patient-derived glioblastoma stem cells. J Exp Ther Oncol. 2010; 8:247-260.

17. Stang A. Critical evaluation of the Newcastle-Ottawa scale for the assessment of the quality of nonrandomized studies in meta-analyses. Eur J Epidemiol. 2010; 25:603-605.

18. Louis DN, Perry A, Reifenberger G, von Deimling A, Figarella-Branger D, Cavenee WK, Ohgaki H, Wiestler OD, Kleihues P, Ellison DW. The 2016 World Health Organization Classification of Tumors of the Central Nervous System: a summary. Acta Neuropathol. 2016; 131:803-820.

19. Arnold SD, Forman LM, Brigidi BD, Carter KE, Schweitzer HA, Quinn HE, Guill AB, Herndon JE 2nd, Raynor RH. Evaluation and characterization of generalized anxiety and depression in patients with primary brain tumors. Neurooncology. 2008; 10:171-181.

20. Litofsky NS, Farace E, Anderson F Jr, Meyers CA, Huang W, Laws ER Jr; Glioma Outcomes Project Investigators. Depression in patients with high-grade glioma: results of the Glioma Outcomes Project. Neurosurgery. 2004; 54:358366; discussion 366-357.

21. Goebel S, Kaup L, Mehdorn HM. Measuring preoperative anxiety in patients with intracranial tumors: the Amsterdam preoperative anxiety and information scale. J Neurosurg Anesthesiol. 2011; 23:297-303.

22. Brown PD, Ballman KV, Rummans TA, Maurer MJ, Sloan JA, Boeve BF, Gupta L, Tang-Wai DF, Arusell RM, Clark MM, Buckner JC. Prospective study of quality of life in adults with newly diagnosed high-grade gliomas. J Neurooncol. 2006; 76:283-291.

23. Kaplan CP, Miner ME. Relationships: importance for patients with cerebral tumours. Brain Inj. 2000; 14:251-259.

24. McGovern PC, Lautenbach E, Brennan PJ, Lustig RA, Fishman NO. Risk factors for postcraniotomy surgical site infection after 1,3-bis (2-chloroethyl)-1-nitrosourea (Gliadel) wafer placement. Clin Infect Dis. 2003; 36:759-765.

25. Rotenstein LS, Ramos MA, Torre M, Segal JB, Peluso MJ, Guille C, Sen S, Mata DA. Prevalence of depression, depressive symptoms, and suicidal ideation among amedical students: a systematic review and meta-Analysis. JAMA. 2016; 316:2214-2236.

26. Mata DA, Ramos MA, Bansal N, Khan R, Guille C, Di Angelantonio E, Sen S. Prevalence of depression and depressive symptoms among resident physicians: a systematic review and meta-analysis. JAMA. 2015; 314:2373-2383.
27. Higgins JP, Thompson SG. Quantifying heterogeneity in a meta-analysis. Stat Med. 2002; 21:1539-1558.

28. Higgins JP, Thompson SG, Deeks JJ, Altman DG. Measuring inconsistency in meta-analyses. BMJ. 2003; 327:557-560.

29. Egger M, Davey Smith G, Schneider M, Minder C. Bias in meta-analysis detected by a simple, graphical test. BMJ. 1997; 315:629-634.

30. Sterne JA, Egger M. Funnel plots for detecting bias in metaanalysis: guidelines on choice of axis. J Clin Epidemiol. 2001; 54:1046-1055.

31. Sterne JA, Juni P, Schulz KF, Altman DG, Bartlett C, Egger M. Statistical methods for assessing the influence of study characteristics on treatment effects in 'metaepidemiological' research. Stat Med. 2002; 21:1513-1524.

32. van Houwelingen HC, Arends LR, Stijnen T. Advanced methods in meta-analysis: multivariate approach and metaregression. Stat Med. 2002; 21:589-624.

33. Jenkins LM, Drummond KJ, Andrewes DG. Emotional and personality changes following brain tumour resection. J Clin Neurosci. 2016; 29:128-132.

34. Anderson SI, Taylor R, Whittle IR. Mood disorders in patients after treatment for primary intracranial tumours. Br J Neurosurg. 1999; 13:480-485.

35. Bunevicius A, Deltuva V, Tamasauskas S, Tamasauskas A, Bunevicius R. Screening for psychological distress in neurosurgical brain tumor patients using the Patient Health Questionnaire-2. Psychooncology. 2013; 22:1895-1900.

36. Chang SM, Parney IF, McDermott M, Barker FG 2nd, Schmidt MH, Huang W, Laws ER Jr, Lillehei KO, Bernstein M, Brem H, Sloan AE, Berger M; Glioma Outcomes Investigators. Perioperative complications and neurological outcomes of first and second craniotomies among patients enrolled in the Glioma Outcome Project. J Neurosurg. 2003; 98:1175-1181.

37. Edelstein K, Coate L, Massey C, Jewitt NC, Mason WP, Devins GM. Illness intrusiveness and subjective wellbeing in patients with glioblastoma. J Neurooncol. 2016; 126:127-135.

38. Giovagnoli AR, Silvani A, Colombo E, Boiardi A. Facets and determinants of quality of life in patients with recurrent high grade glioma. J Neurol Neurosurg Psychiatry. 2005; 76:562-568.

39. Goebel S, Mehdorn HM. Measurement of psychological distress in patients with intracranial tumours: the NCCN distress thermometer. J Neurooncol. 2011; 104:357-364.

40. Goebel S, Mehdorn HM. Development of anxiety and depression in patients with benign intracranial meningiomas: a prospective long-term study. Support Care Cancer. 2013; 21:1365-1372.

41. Grant R, Slattery J, Gregor A, Whittle IR. Recording neurological impairment in clinical trials of glioma. J Neurooncol. 1994; 19:37-49. 
42. Janda M, Steginga S, Langbecker D, Dunn J, Walker D, Eakin E. Quality of life among patients with a brain tumor and their carers. J Psychosom Res. 2007; 63:617-623.

43. Kilbride L, Smith G, Grant R. The frequency and cause of anxiety and depression amongst patients with malignant brain tumours between surgery and radiotherapy. J Neurooncol. 2007; 84:297-304

44. Leistner SM, Klotsche J, Dimopoulou C, Athanasoulia AP, Roemmler-Zehrer J, Pieper L, Schopohl J, Wittchen HU, Stalla GK, Fulda S, Sievers C. Reduced sleep quality and depression associate with decreased quality of life in patients with pituitary adenomas. Eur J Endocrinol. 2015; 172:733-743.

45. Pringle AM, Taylor R, Whittle IR. Anxiety and depression in patients with an intracranial neoplasm before and after tumour surgery. Br J Neurosurg. 1999; 13:46-51.

46. Rahman Z, Wong CH, Dexter M, Olsson G, Wong M, Gebsky V, Nahar N, Wood A, Byth K, King M, Bleasel AB. Epilepsy in patients with primary brain tumors: the impact on mood, cognition, and HRQOL. Epilepsy Behav. 2015; 48:88-95.

47. Wellisch DK, Kaleita TA, Freeman D, Cloughesy T, Goldman J. Predicting major depression in brain tumor patients. Psychooncology. 2002; 11:230-238.

48. Wenz H, Wenz R, Ehrlich G, Groden C, Schmieder K, Fontana J. Patient characteristics support unfavorable psychiatric outcome after treatment of unruptured intracranial aneurysms. Acta Neurochir (Wien). 2015; 157:1135-1145; discussion 1145

49. van der Vossen S, Schepers VP, Berkelbach van der Sprenkel JW, Visser-Meily JM, Post MW. Cognitive and emotional problems in patients after cerebral meningioma surgery. J Rehabil Med. 2014; 46:430-437.

50. Andrewes HE, Drummond KJ, Rosenthal M, Bucknill A, Andrewes DG. Awareness of psychological and relationship problems amongst brain tumour patients and its association with carer distress. Psychooncology. 2013; 22:2200-2205.

51. D'Angelo C, Mirijello A, Leggio L, Ferrulli A, Carotenuto V, Icolaro N, Miceli A, D'Angelo V, Gasbarrini G, Addolorato G. State and trait anxiety and depression in patients with primary brain tumors before and after surgery: 1-year longitudinal study. J Neurosurg. 2008; 108:281-286.

52. Armstrong CL, Goldstein B, Cohen B, Jo MY, Tallent EM. Clinical predictors of depression in patients with lowgrade brain tumors: consideration of a neurologic versus a psychogenic model. J Clin Psychol Med Settings. 2002; 9:97-107.

53. Davies E, Clarke C, Hopkins A. Malignant cerebral glioma-II: perspectives of patients and relatives on the value of radiotherapy. BMJ. 1996; 313:1512-1516.

54. Hickmann AK, Nadji-Ohl M, Haug M, Hopf NJ, Ganslandt O, Giese A, Renovanz M. Suicidal ideation, depression, and health-related quality of life in patients with benign and malignant brain tumors: a prospective observational study in 83 patients. Acta Neurochir (Wien). 2016; 158:1669-1682.

55. Santini B, Talacchi A, Squintani G, Casagrande F, Capasso R, Miceli G. Cognitive outcome after awake surgery for tumors in language areas. J Neurooncol. 2012; 108:319-326.

56. Rooney AG, van Nieuwenhuizen D, Reijneveld JC, Grant $\mathrm{R}$. Female gender is not a proven risk factor for depression in glioma. J Neurooncol. 2009; 95:449.

57. Mainio A, Hakko H, Timonen M, Niemel A, Koivukangas J, Räsänen P. Depression in relation to survival among neurosurgical patients with a primary brain tumor: a 5-year follow-up study. Neurosurgery. 2005; 56:1234-1242.

58. Giovagnoli AR, Tamburini M, Boiardi A. Quality of life in brain tumor patients. J Neurooncol. 1996; 30:71-80.

59. Miller IW, Bishop S, Norman WH, Maddever H. The modified Hamilton rating scale for depression: reliability and validity. Psychiatry Res. 1985; 14:131-142.

60. Zigmond AS, Snaith RP. The hospital anxiety and depression scale. Acta Psychiatr Scand. 1983; 67:361-370.

61. Löwe B, Unützer J, Callahan CM, Perkins AJ, Kroenke K. Monitoring depression treatment outcomes with the patient health questionnaire-9. Med Care. 2004; 42:1194-1201.

62. Spitzer RL, Kroenke K, Williams JB. Validation and utility of a self-report version of PRIME-MD: the PHQ primary care study. Primary Care Evaluation of Mental Disorders. Patient Health Questionnaire. JAMA. 1999; 282:1737-1744.

63. Beck AT, Steer RA, Carbin MG. Psychometric properties of the Beck Depression Inventory: twenty-five years of evaluation. Clin Psychol Rev. 1988; 8:77-100.

64. Beck AT, Steer RA, Brown GK. (1996). Manual for the Beck depression inventory-II. San Antonio, TX: Psychological Corporation.

65. Lewinsohn PM, Seeley JR, Roberts RE, Allen NB. Center for Epidemiologic Studies Depression Scale (CES-D) as a screening instrument for depression among communityresiding older adults. Psychol Aging. 1997; 12:277-287.

66. Zung WW. A self-rating depression scale. Arch Gen Psychiatry. 1965; 12:63-70.

67. Curran SL, Andrykowski MA, Studts JL. Short form of the Profile of Mood States (POMS-SF): psychometric information. Psychol Assess. 1995; 7:80.

68. Ware JE Jr, Sherbourne CD. The MOS 36-item short-form health survey (SF-36): I. Conceptual framework and item selection. Med Care. 1992:473-483.

69. Kerr LK, Kerr LD. Screening tools for depression in primary care. West J Med. 2001; 175:349.

70. Rooney AG, McNamara S, Mackinnon M, Fraser M, Rampling R, Carson A, Grant R. The frequency, longitudinal course, clinical associations, and causes of emotional distress during primary treatment of cerebral glioma. Neuro Oncol. 2013; 15:635-643. 
71. Lehtinen V, Joukamaa M. Epidemiology of depression: prevalence, risk factors and treatment situation. Acta Psychiatr Scand Suppl. 1994; 377:7-10.

72. Anderson RJ, Freedland KE, Clouse RE, Lustman PJ. The prevalence of comorbid depression in adults with diabetes: a meta-analysis. Diabetes Care. 2001; 24:1069-1078.

73. Burgess C, Cornelius V, Love S, Graham J, Richards M, Ramirez A. Depression and anxiety in women with early breast cancer: five year observational cohort study. BMJ. 2005; 330:702.

74. Guo X, Xu J, E Y, Yu Z, Sun T. Correlation between hormone receptor status and depressive symptoms in patients with metastatic breast cancer. Oncotarget. 2017; 8:50774-50781. https://doi.org/10.18632/ oncotarget.15037.

75. Zhuang QS, Shen L, Ji HF. Quantitative assessment of the bidirectional relationships between diabetes and depression. Oncotarget. 2017; 8:23389-23400. https://doi.org/10.18632/ oncotarget. 15051 .
76. Wu Y, Si R, Yang S, Xia S, He Z, Wang L, He Z, Wang Q, Tang H. Depression induces poor prognosis associates with the down-regulation brain derived neurotrophic factor of serum in advanced small cell lung cancer. Oncotarget. 2016; 7:85975-85986. https://doi.org/10.18632/oncotarget.13291.

77. Williams JW, Pignone M, Ramirez G, Stellato CP. Identifying depression in primary care: a literature synthesis of case-finding instruments. Gen Hosp Psychiatry. 2002; 24:225-237.

78. Kan C, Silva N, Golden SH, Rajala U, Timonen M, Stahl $\mathrm{D}$, Ismail K. A systematic review and meta-analysis of the association between depression and insulin resistance. Diabetes Care. 2013; 36:480-489.

79. Kessler RC. The categorical versus dimensional assessment controversy in the sociology of mental illness. J Health Soc Behav. 2002; 43:171-188.

80. Draguns JG, Tanaka-Matsumi J. Assessment of psychopathology across and within cultures: issues and findings. Behav Res Ther. 2003; 41:755-776. 